\title{
Optimization of Fertlizer Rates for Wheat Crop using Fuzzy Expert System
}

\author{
Harsimranjit Singh \\ Research Scholar \\ Department ECE \\ ACET, ASR
}

\author{
Narinder Sharma \\ Professor \\ Department ECE \\ ACET, ASR
}

\begin{abstract}
In this work it is proposed to provide proper nutrition to soil, which is very essential for satisfactory crop growth and production. The use of soil tests can help us to determine the status of available nutrients in soil, this paper aims at calculating required amount of NPK fertilizers for soil accordingly NPK levels actually found during soil test. Applying fuzzy based rules in a fuzzy expert system we here are developing fertilizer recommendations needed to achieve optimum crop production. Efficient application of the correct amounts of fertilizers for the supply of the nutrients is an important part of achieving profitable yields. The profit potential for farmers depends on producing enough crops per acre to keep production costs below the selling price. Moreover optimizing fertilizer will help us preventing environmental effects like water pollution and health effects.
\end{abstract}

\section{Keywords}

NPK, Fuzzy Expert System, Fertilizers, Crop production.

\section{INTRODUCTION}

Human civilization has come long way, since they have been living forest and living on wild berries. Later they discovered the art of hunting for their survival. Over the years there has been lot of research in area of agriculture. Lately they came to explore importance of soil, which was very important for agriculture. Soil plays very key role for growth of plants and crop. Soil as medium for growth has come under lot of stress due to availability of land and demand of food and fiber.

Plants mine soil for 13 nutrients and out of which 3 primary nutrients required are Nitrogen, Phosphorous and Potassium. With increasing in mining this has resulted in increase in depletion of essential nutrients from soil which can be fulfilled by applying fertilizers. Moreover Fertilizer application is required to replace crop land nutrients that have been consumed by previous plant growth. .On average in wheat, rice crop sown alternately losses $600 \mathrm{~kg} / \mathrm{Ha}$ of NPK fertilizers from soil. It is also essential for economic yields. One way to redeem deficiency of essential nutrients for soil is application of fertilizers to soil. These fertilizer however if applied in adequately can cause huge concern for environment which are discussed below. So our initiative is to provide such a system which will provide exact recommendation of fertilizers for a crop. The three main components of fertilizer that are required for soil are nitrogen $(\mathrm{N})$ and phosphorus $(\mathrm{P})$ and Potassium (K).

\section{EXCESSIVE FERTILIZATION CONCERNS}

The excessive fertilization may leads water pollution and health concern for man and animals and have many more very adverse effects.

\subsection{Environmental concerns}

Some of them are discussed in the following

- Nutrients in fertilizers can leach into groundwater or be carried by runoff or erosion into surface water, degrading water quality.

- Nitrate concentrations above 10 milligrams per litre of water (the public health safety limit) can negatively affect human and animal health, especially that of infants and young livestock.

- Phosphorus that is transported to surface waters can cause blooms of algae and eutrophication. Soluble phosphorus can contaminate groundwater.

- Excess potassium in feed or water can cause animal health problems including grass tetany and reproductive difficulties [20].

\subsection{Crop yield concern}

The inadequate fertilization to soils also effects crop yield and adds to cost of farmer. Here we are discussing relation between fertilizer application and potential yield which is schematically described in the following curve [19]

\section{Crop Response To Fertilizers Application}

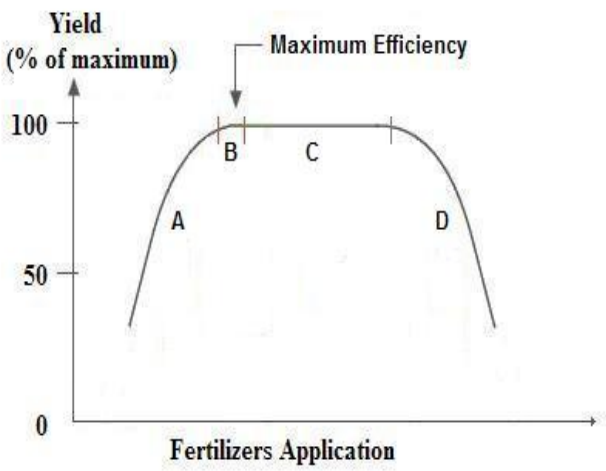

Figure 1: Yield Response Vs Fertilizer application curve

Explanation to the plot: When no fertilizer is applied, yield is at its minimum. At first, yield increases as fertilizer application rate increases (A), then yield reaches a maximum (B).From this point on, any addition of extra fertilizer does not increase the yield (C).When fertilizer application rates are too high, salinity damages and specific nutrient toxicities occur, and yield declines (D) [19].Therefore to get best result fertilizer program is developed that is specific to wheat crop. 


\section{FUZZY EXPERT SYSTEM}

Over the years various expert systems have been developed some of them like an expert system for weed control decision making in sunflower [2], Integrated Pest Management System using Fuzzy Expert System [3], CALEX Cotton: an integrated expert system for cotton production and management etc. Here in this research a fuzzy based expert will be developed for fertilizer optimization with following implementation steps.

\subsection{Soil test}

For this purpose firstly soil test is done by taking samples of soil in 250 Grams each from four corners and from extreme middle coordinate of field, further mixing together and taking 250 Grams. Further this sample is lab tested to know present levels of NPK in soil. After soil test being implemented, we can use a proposed Fuzzy Based Expert System to get optimize values of NPK fertilizers needed by wheat crop.

\subsection{Fuzzy based expert system for fertilizer}

Expert system is computer program that basically stimulates decision making power of human expert. In expert system there two parts knowledge base where facts and figure are recorded and secondly inherence system which uses knowledge base [21], to come to new facts from users query given at input. The block diagram of Fuzzy Expert system developed is illustrated in Fig 2. The mamdani system of fuzzy is being used for this application. The mamdani inherence system is useful when applying fuzzy logic to control of system[9]. The expert system is given crisp value as input i.e. fuzzification via membership functions, rule base , rule evaluation, aggregation and defuzzification for purpose of creating the crisp values at output. Here three input variables are taken i.e. present levels of nitrogen, phosphorous and potassium level in soil. The need of nitrogen, phosphorous and potassium levels were defined as output variables.

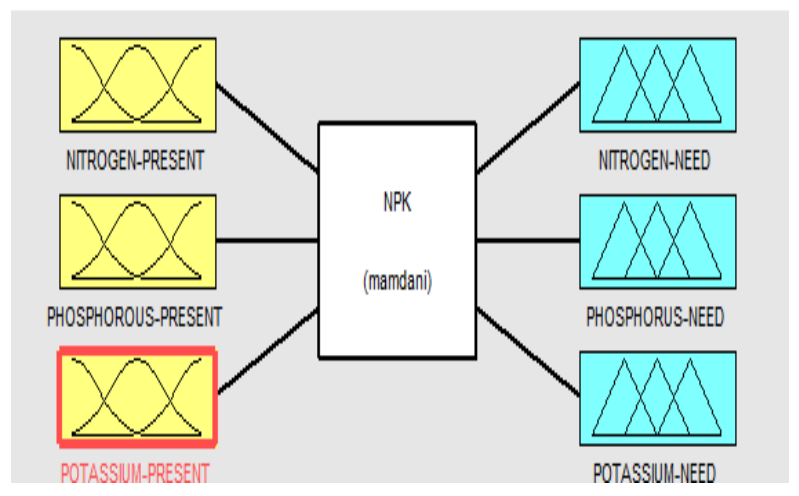

Figure2: Fuzzy based Fertilizer Expert system

The range of input and output variables were selected by examining data. The universe disclosure were taken as for input nitrogen, phosphorous and potassium i.e. $(0-1 \mathrm{Kg} / \mathrm{Ha})$, $(0-50 \mathrm{Kg} / \mathrm{Ha})$ and $(0-100 \mathrm{Kg} / \mathrm{Ha})$ taken respectively. Similarly at output needed levels of nitrogen, phosphorous and potassium that were taken are $(0-130 \mathrm{Kg} / \mathrm{Ha}),(0-100 \mathrm{Kg} / \mathrm{Ha})$ and $(0-50 \mathrm{Kg} / \mathrm{Ha})$ respectively. The interrelation between inputs and outputs, both are crisp values, is made by linguistic transformation of input membership functions, implication and aggregation using the rule base, and defuzzification of the linguistic output to values representing need of amount of each fertilizer.

\subsubsection{MembershipFunctions}

The membership functions that are adopted either trapezoidal or triangular membership accordingly needed. The rules are formulated here using MATLAB fuzzy tool, a simple Mamdani system which is very useful when applying fuzzy logic to control of system [9]. There are three input variables taken nitrogen, phosphorous, potassium present already in soil which are partitioned into three, four and two sets respectively each. These input variables are represented in triangular shapes as shown in Fig 3(a-c). The nitrogen, phosphorous, potassium needed are partitioned into three, four and two sets each and are represented in triangular shapes as shown in Fig 3 (d-f).

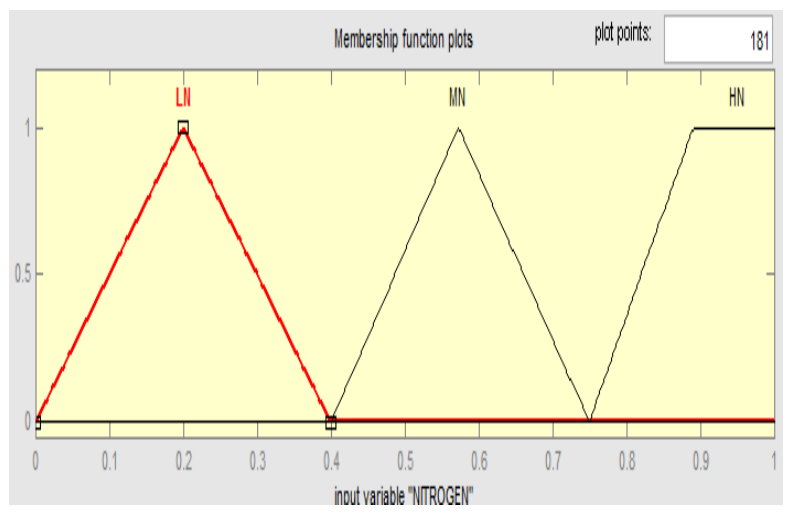

Figure 3(a) Nitrogen present

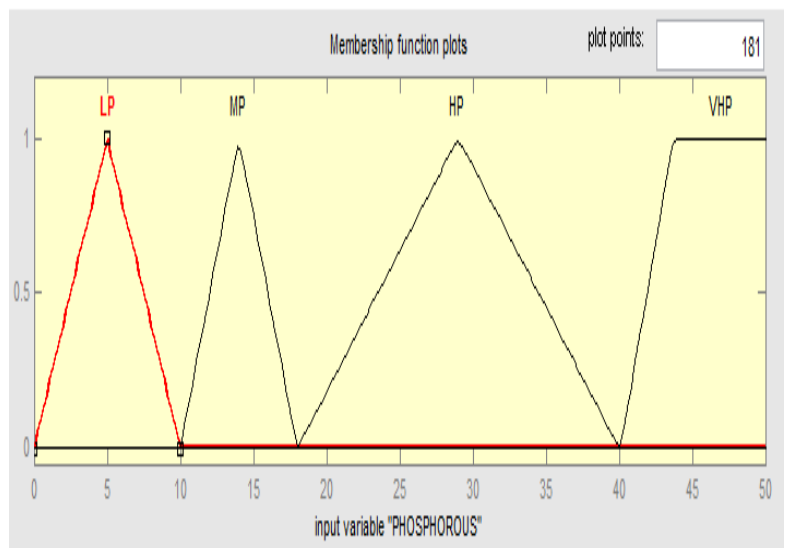

Figure 3(b) Phosphorous present

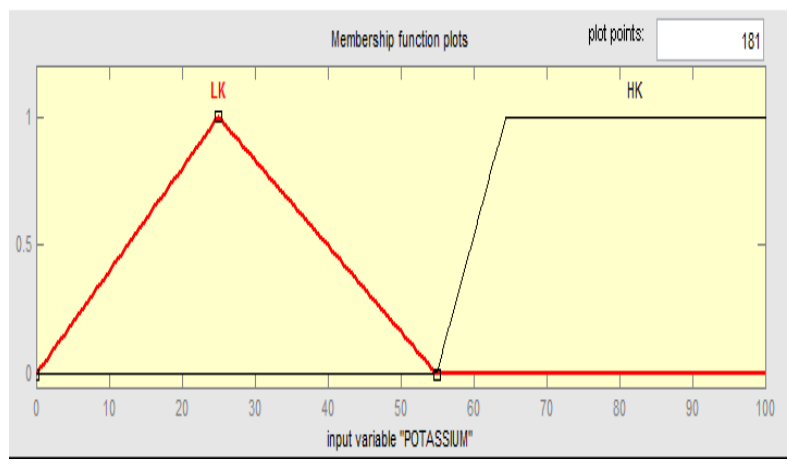

Figure 3(c) Potassium present 


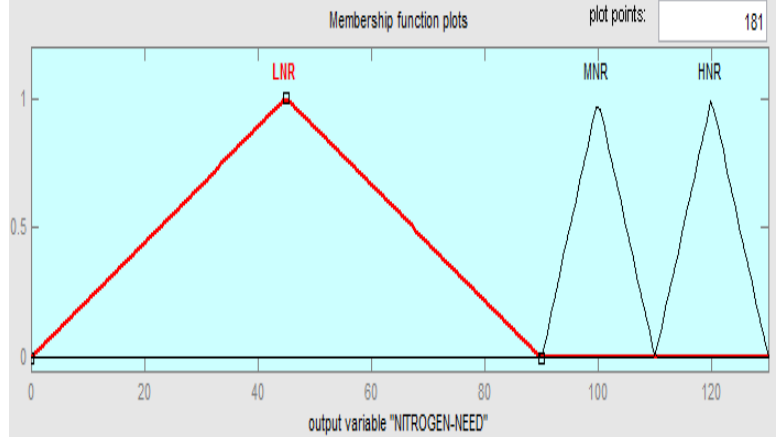

Figure 3(a) Nitrogen need

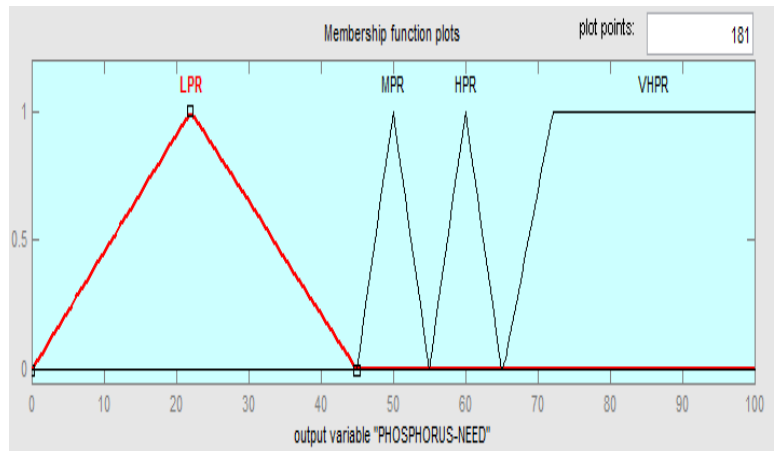

Figure 3(b) Phosphorous need

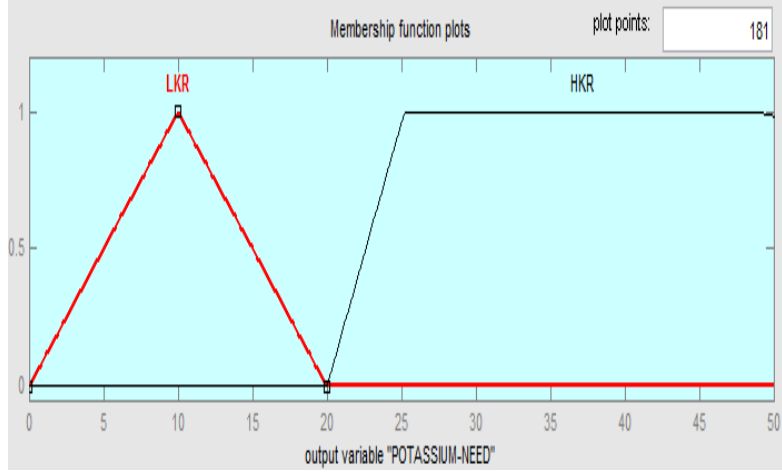

Figure 3(c) Potassium need
Table I: Depicting levels of NPK fertilizer found in soil test and corresponding recommended levels of NPK fertilizer

*N - Nitrogen, $\mathbf{P}$ - Phosphorous, $\mathrm{K}$ - Potassium, L - Low, H High, M -Medium, VH -Very High

\begin{tabular}{|c|c|c|c|c|c|}
\hline \multicolumn{3}{c}{$\begin{array}{c}\text { INPUT } \\
\text { VARIABLES }\end{array}$} & \multicolumn{3}{c|}{ OUTPUT } \\
(NPK PRESENT IN SOIL) & (NPK LEVEL NEEDED) \\
\hline N & P & K & N & P & K \\
\hline L & L & L & H & VH & H \\
\hline L & L & H & H & VH & L \\
\hline L & M & L & H & H & H \\
\hline L & M & H & H & H & L \\
\hline L & H & L & H & M & H \\
\hline L & H & H & H & M & L \\
\hline L & VH & L & H & L & H \\
\hline L & VH & H & H & L & L \\
\hline M & L & L & M & VH & H \\
\hline M & L & H & M & VH & L \\
\hline M & M & L & M & H & H \\
\hline M & M & H & M & H & L \\
\hline M & H & L & M & M & H \\
\hline M & H & H & M & M & L \\
\hline M & VH & L & M & L & H \\
\hline M & VH & H & M & L & L \\
\hline H & L & L & L & VH & H \\
\hline H & L & H & L & VH & L \\
\hline H & M & L & L & H & H \\
\hline H & M & H & L & H & L \\
\hline H & H & L & L & M & H \\
\hline H & H & H & L & M & L \\
\hline H & VH & L & L & L & H \\
\hline H & VH & H & L & L & L \\
\hline & & & & & \\
\hline
\end{tabular}

\subsubsection{Fuzzy rules used}

The 24 basic fuzzy rules are taken to describe very useful relations between the three inputs of NPK present in soil and three outputs of NPK needed in soil. Here below few of them given in following

1. If (Nitrogen is Low) and (Phosphorous is Low) and (Potassium is Low) then (Nitrogen is High needed) (Phosphorous is Very high needed) (Potassium is High needed)

2. If (Nitrogen is Low) and (Phosphorous is Low) and (Potassium is High) then (Nitrogen is High needed) (Phosphorous is Very high needed) (Potassium is Low needed)

3. If (Nitrogen is Low) and (Phosphorous is Medium) and (Potassium is Low) then (Nitrogen is High needed) (Phosphorous is High needed) (Potassium is High needed)

4. If (Nitrogen is Low) and (Phosphorous is Medium) and (Potassium is High) then (Nitrogen is High needed) (Phosphorous is High needed) (Potassium is Low needed) 
5. If (Nitrogen is Low) and (Phosphorous is High) and (Potassium is Low) then (Nitrogen is High needed) (Phosphorous is Medium needed) (Potassium is High needed)

6. If (Nitrogen is Low) and (Phosphorous is High) and (Potassium is High) then (Nitrogen is High needed) (Phosphorous is Medium needed) (Potassium is Low needed)

7. If (Nitrogen is Low) and (Phosphorous is Very High) and (Potassium is Low) then (Nitrogen is High needed) (Phosphorous is Low needed) (Potassium is High needed)

8. If (Nitrogen is Low) and (Phosphorous is Very High) and (Potassium is High) then (Nitrogen is High needed) (Phosphorous is Low needed) (Potassium is Low needed)

9. If (Nitrogen is Medium) and (Phosphorous is Low) and (Potassium is Low) then (Nitrogen is Medium needed) (Phosphorous is Very High needed) (Potassium is High needed)

10. If (Nitrogen is Medium) and (Phosphorous is Low) and (Potassium is High) then (Nitrogen is Medium needed) (Phosphorous is Very High needed) (Potassium is Low needed)

11. If (Nitrogen is Medium) and (Phosphorous Medium) and (Potassium is Low) then (Nitrogen is Medium needed) (Phosphorous is High needed) (Potassium is High needed)

\section{RESULTS}

The results were taken for various levels of NPK values found during soil test and correspondingly required levels of NPK were calculated using Fuzzy Based Expert system. Following are some of input levels of NPK present that were taken, recommendation levels for NPK needed were calculated and are shown in TABLE II.

Table II: Depicting testing of Expert system

\begin{tabular}{|c|c|c|c|c|c|}
\hline \multicolumn{3}{|c|}{$\begin{array}{c}\text { NPK PRESENT IN SOIL } \\
(\mathrm{Kg} / \mathrm{Ha})\end{array}$} & \multicolumn{3}{|c|}{$\begin{array}{c}\text { NPK NEED IN SOIL } \\
(\mathrm{Kg} / \mathrm{Ha})\end{array}$} \\
\hline $\mathbf{N}$ & $\mathbf{P}$ & $\mathbf{K}$ & $\mathbf{N}$ & $\mathbf{P}$ & $\mathbf{K}$ \\
\hline 0.5 & 25 & 50 & 100 & 50 & 35 \\
\hline 0.9 & 41 & 88 & 45 & 22 & 10 \\
\hline 0.1 & 2.6 & 10 & 120 & 83 & 35 \\
\hline
\end{tabular}

A snapshot of Software result is here demonstrated in Fig 4, depicting when levels $\mathrm{N}, \mathrm{P}, \mathrm{K}$ in soil are found to be $0.5 \mathrm{Kg} / \mathrm{Ha}, 25 \mathrm{Kg} / \mathrm{Ha}$ and $50 \mathrm{Kg} / \mathrm{Ha}$ correspondingly values of needed levels came out to be $100 \mathrm{Kg} / \mathrm{Ha}, 50 \mathrm{Kg} / \mathrm{Ha}$ and 35 $\mathrm{Kg} / \mathrm{Ha}$ for $\mathrm{N}, \mathrm{P} \& \mathrm{~K}$

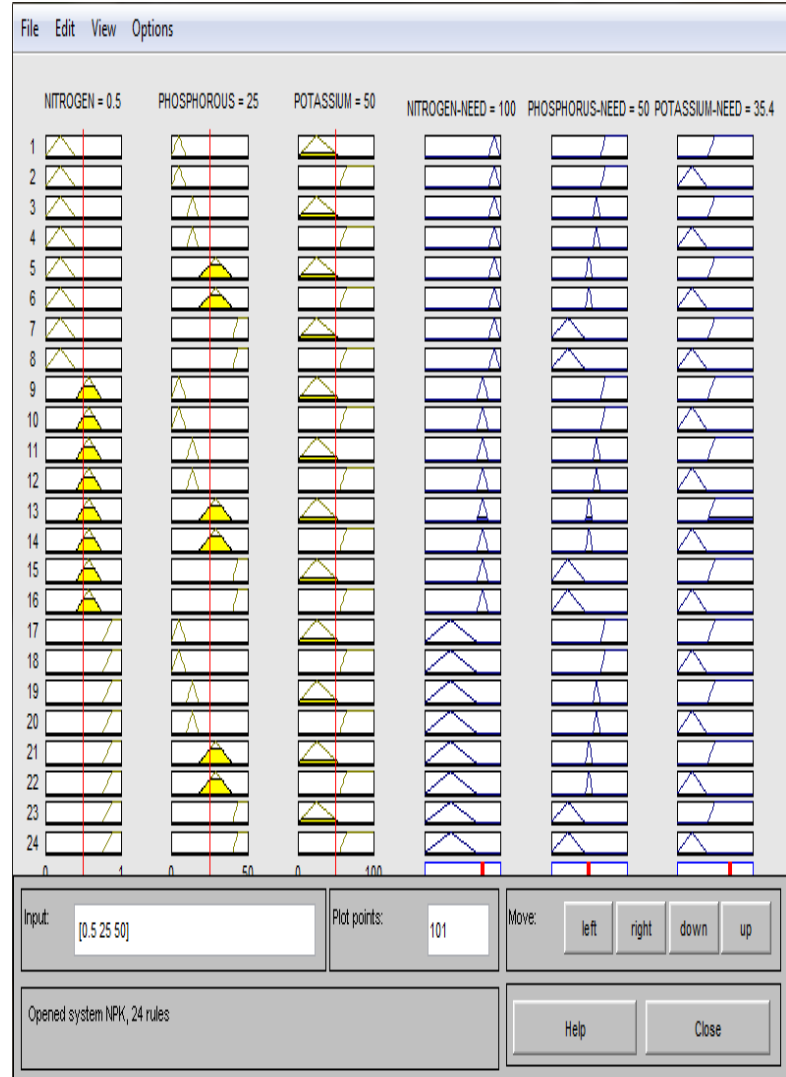

Figure4. Software Snapshot of Expert system

\section{CONCLUSION}

A Fuzzy Based Expert system for fertilizer optimization is being developed and proposed wherein are able to calculate that values of NPK fertilizers needed in soil for wheat crop, knowing levels of NPK levels present in soil. Applying precise and almost exact amount of NPK fertilizers needed in soil accordingly into crop would helps farmers to reap the maximum returns from his crop, while reducing his fertilizer costs. Reducing fertilizers intake accordingly will reduce fertilizers intake. And would prevent over fertilization which damages crop yield and make soil degraded. Overall benefit it prevents hazard effects that are caused to environment.

\section{ACKNOWLEDGMENT}

Our thanks to the agriculture department experts who have contributed towards providing guidance and data much needed in research, which was very helpful for this research work.

\section{REFERENCES}

[1] A. Ed-dahhak1, M. Guerbaoui1, Y. ElAfou1, M. Outanoute1, A. Lachhab1,L. Belkoura2 and B. Bouchikhil, " Implementation of Fuzzy Controller to Reduce Water Irrigation in Greenhouse using Labview " International Journal of Engineering and Advanced Technology Studies , September 2013,Vol.1 No. 2, pp.12-22.

[2] A. J. Castro and Garcia - Torres, "SEMAGI - an expert system for weed control decision making in sunflower", Crop Protection Elsevier Science Ltd.(1995), Vol. 14, No.7, pp. 543-548.

[3] Fadzilah Siraj \& Nureize Arbaiy, "Integrated Pest Management System Using Fuzzy Expert System”, In: Proceedings of Knowledge Management International 
Conference \& Exhibition (KMICE), Malaysia(2006), pp.169-176.

[4] G. Delgado, V. Aranda, J. Calero, M. SánchezMarañón, J. M. Serrano, D. Sánchez and M. A. Vila, "Building a fuzzy logic information network and a decision-support system for olive cultivation in Andalusia" Spanish Journal of Agricultural Research 2008 6(2), pp.252-263.

[5] G.N.R. Prasad, Dr. A Vinaya Babu, "A Study of Various Expert System in Agriculture", Georgian Electronic Scientific Journal:Computer Science \&Telecommunication 2006 No.4(11) pp.81-86.

[6] Harvinder S. Saini, Raj Kamal and A. N. Sharma, "Web Based Fuzzy Expert System for Integrated Pest Management in Soyabean", International journal Of Information technology2002, Vol 8, No. 2, pp.54-74.

[7] Howard W. Beck, Pierce Jones and J.W. Jones (1989)," SOYBUG:An expert system for soyabean insect pest management", Agricultural Systems, URLhttp://www.sciencedirect.com/science/article/pii 1989,Vol. 30, Issue, pp.269-286.

[8] K.N. Singh, N.S. Raju, A. Subba Rao, Abhishek Rathore, Sanjay Srivastava, R.K. Samanta and A.K. Maji, "Optimum Doses of Nutrients for targeted yield through soil fertility maps in Andhra Pradesh (AP)" J fnd Soc Agriculture Statist 2005. 59(2), pp.131-140.

[9] M. Guerbaoui1,A. Ed-dahhak2, Y. ElAfou1, 3, A. Lachhab2, L. Belkoura3 andB.Bouchikhi1, "Implementation of Direct Fuzzy Controller in Greenhouse based on Labview" International Journal of Electrical and Electronics Engineering Studies, September 2013 Vol.1 No.1, pp.1-13.

[10] M. Guerbaoui, Y. el afou,A. ED-Dahhak, A. Lachhabb. Bouchikhi, "PC-Based automated Drip Irrigation System", International Journal of Engineering Science and Technology, January 2013 (IJEST) ISSN: 09755462, Vol. 5 No.01, pp.221-225.

[11] Peter B Goodell, Richerd E. Plant, Thomos A. Kerby, Joyce F. Strand, L. Ted Wilson, Lowell Zelinski, Julli A. young, Andrew Corbett, R.D. Horrocks, Ronold N. Vargas, "CALEX/ Cotton: an integrated expert system for cotton production and management", California Agriculture(1990), Vol 44, No. 5, pp18-21.

[12] Philomine Roseline, Clarence JM Tauro, N Ganesan, "Design and Development of Fuzzy Expert System for
Integrated Disease Management in Finger Millets" International Journal of Computer Applications (0975 8887) October 2012, Volume 56- No.1, pp.31.

[13] P. Javadi Kia, A. Tabatabaee Far, M. Omid, R. Alimardani and L. Naderlo, Intelligent Control Based Fuzzy Logic for Automation of Greenhouse "Irrigation System and Evaluation in Relation to Conventional Systems", World Applied Sciences Journal 2009, Vol 6 (1) , pp.16-23.

[14] Savita Kolhe, Raj Kamal, Harvinder S. Saini and G.K. Gupta , "A web-based intelligent disease-diagnosis system using a new fuzzy-logic based approach for drawing the inferences in crops", Journal of Computers and Electronics in Agriculture, year 2011, volume 76, pp $16-27$.

[15] Qin Song,Fukuan Zhao, Yujun Zheng "A Tabu Search Approach to Fuzzy Optimization of Camellia Oleifera Fertilization" IFIP Advances in Information and Communication Technology 2011,Volume 344, pp.125130

[16] S.Abdullah1, A. A. Bakar, N. Mustafa, M. Yusuf, S. Abdullah and A.R Hamdan" Fuzzy Knowledge Modeling for Image-based Paddy Disease Diagnosis Expert System", In Proceedings of the International Conference on Electrical Engineering and Informatics Institute Technology Bandung, Indonesia,June 17-19, 2007, pp.642-644.

[17] Sonal Dubey, R.K. Pandey, S.S. Gautam, "Literature Review on Fuzzy Expert System in Agriculture" International Journal of Soft Computing and Engineering (IJSCE) ISSN: 2231-2307, January 2013, Volume-2, Issue-6, pp.289-291.

[18] Virparia P.V. “A Web Based Fuzzy Expert System for Insect Pest Management in Groundnut Crop 'Prajna"'Journal of Pure \& Applied Sciences, (2007) Vol 15, pp.36-41.

[19] http://www.smart-fertilizer.com/fertilizer-applicationrates.

[20] http://www.uwex.edu/farmasyst/states/nyfertilizermgmt. pdf

[21] http://en.wikipedia.org/wiki/Expert_system 